\title{
Knowledge Transfer in a Municipality Study on Baby Boomer Exodus from the Workforce
}

\author{
Ivy Cummings-White \\ Resources Consultant \\ North Texas Municipality \\ Texas, USA
}

\author{
Ify S. Diala \\ Contributing Faculty \\ Walden University \\ Minneapolis MN, USA
}

\begin{abstract}
A substantial number of Baby Boomers are entering retirement and will impact both public and private sector organizations. To address this upcoming challenge, organizations must establish mechanisms to identify, capture, and transfer Boomer knowledge. This qualitative phenomenological study was designed to explore the Baby Boomer phenomena through the perceptions and experiences of Boomer leaders that are eligible to retire from a North Texas Municipality. Fourteen semi-structured face-to-face interviews identified eight core themes that provide opportunities for leadership to assess organizational readiness. The eight core themes consists of obtaining perceptions from the sample size of the following: meaning of institutional knowledge, capturing institutional knowledge in current position, knowing what knowledge to capture, current methods of capturing and transferring knowledge, usefulness of written procedures, obstacles in retaining knowledge, impact of the leaving the organization, and suggestions to capture and transfer knowledge.
\end{abstract}

Keywords: knowledge transfer; knowledge management; workforce planning; Succession planning; retirement; baby boomers

\section{INTRODUCTION}

In the twenty-first century workplace, four generations are at work together. In the United States, the number of individuals 65 and older is expected to double from 37 million in 2010 to exceed 70 million in 2030 [1]. Born between 1946 and 1964, Boomers were the most prevalent age unit in America in 2007 [2]. A substantial number of Boomers continue to enter retirement, affecting both private and public sectors. These Boomers occupy a vast number of leadership roles, holding a significant amount of institutional knowledge. As Boomers exit an organization, tacit and explicit knowledge leave with them. This emerging phenomenon will have significant influences on organizational abilities to ensure organized transfers of skills and knowledge.

\section{PURPOSE OF THE STUDY}

The objective of this qualitative phenomenological research study was to explore the phenomenon of the Baby Boomer experience related to institutional knowledge accumulation and transfer prior to retirement from the municipality. There is a lack of understanding on how municipalities are addressing the problem. The risk of knowledge loss is a particular concern for the public sector, as job tenure is more prevalent in the public sector.

\section{DISCUSSION}

\subsection{Baby Boomers}

Baby Boomers are the populating group born in the years after World War II. Baby Boomer demographics influenced society. Boomers overcrowded schools in their youth and when they entered the workforce, they set massive records for employment [3]. The Baby Boomers identify with events such as the Civil Rights movement, and Vietnam. Boomers, born between 1946 and 1955, grew up in prosperous booming times. Salaries were increasing, inflation was stable, and unemployment was low. A larger number of schools were built to accommodate growing families, and they were taught nothing was impossible for them to achieve. They were said to be susceptible to becoming workaholics, preferring bigger houses, and better cars [4]. Boomers are known for self- confidence, self-absorption, and are in the forefront based on size alone [5]. Younger Boomers, born between 1956 and 1964, had different experiences. This group arrived at an economic downturn. More than 70 million Baby Boomers have reached the retirement age [1]. Boomer labor shortages are already threatening crucial business sectors [6]. Catalysts for change, Boomers have the power to affect markets and initiate change, unlike generations prior. Baby Boomers are "a generational phenomenon unlike no other" [5] In comparison to other generations, Boomers identified themselves through their occupation and advancement. Boomer workers must generally feel like a member of the team, and possess a high work ethic. They bring a variety of knowledge because of a past of experiencing company changes such as downsizing or streamlining processes.

\subsection{Theoretical Support}

Several popular, theoretical concepts were applicable to this research study. Classical management theory focused on five functions of management [7]. The rational theory encompassed tasks, personnel, and resource allocation [8]. Other important integrated theories included that of $b a$, a review of adult learning styles (andragogy), and generational theories such as $\mathrm{X}$ and $\mathrm{Y}$ were thoroughly documented and explored in-depth in the literature review.

\subsubsection{The classical management theory}

The classical management theory created by Henri Fayol described five functions of management relative to everyday use. Management must be able to plan, organize, command, coordinate, and control functions within the organization. To obtain and transfer knowledge, management will need to devise a strategic plan that would encompass the above functions. The framework of these functions depicted a template for understanding management responsibilities [7].

\subsubsection{The rational theory}

The rational theory perspective concentrated on "what tasks are to be performed, what kinds of personnel are to be hired, and how resources are to be allocated among participants to guide decisions on organization" [8]. This theory was relatable to the study because to transfer knowledge, an 
organization must be in tune with what the job entails as well as personnel trends, knowledge as a resource, and components linked to that organizational knowledge.

\subsubsection{Management by Objective}

The concept of management by objectives was introduced by Peter Drucker, who coined the term knowledge worker. Drucker [9] believed theories and assumptions revolved around people. Increased production of workers as well as how the organization can improve workers benefit both individuals and society. Drucker [10] asserted that management must be competent and have social responsibilities. He believed that people are not costs but resources. Drucker [10] stated that knowledge is the true resource of any organization and it is a social resource. The purpose of knowledge is application of specific skills. Drucker [9] believed that each organization has individuals with various skills and knowledge of different types of tasks. However, knowledge is perishable. Efforts must be made to affirm, learn, and practice constantly so knowledge does not become obsolete.

\subsubsection{The Notion of $\mathrm{Ba}$}

The notion of ba was initiated by Kitaro Nishida, a Japanese philosopher. Nishida [11] sought to understand the nature of knowledge. He believed that knowing about knowledge is quite different from knowing about anything else. Knowing is considered a field of activity known as ba [12]. Nonaka and Konno [13] referred to ba as, "a shared space for emerging relationships". This shared space can be intellectual (shared ideas), physical (office), virtual (email) or a mixture of any of the three. Ba provided the foundation for enhancing single or group knowledge to create knowledge. The theory of existentialism suggested that ba embraced meaning. Moreover, ba is entrenched in the shared space. In this space, personal experiences are acquired as well as experiences of other individuals [13].

\subsubsection{Generational Theory}

Four generations of workers are creating more challenges as well as opportunities worldwide. Generational differences must be understood by management to improve workplace effectiveness. The success of an organization will depend on the organizational ability to embrace an environment with methods to develop, motivate, and retain current personnel, and attract, encourage, develop, and retain the new generation of workers $[14,15]$. Certain generational differences do exist that may cause challenges based on diverse working styles and characteristics $[15,16]$. The primary focuses of studies on generational differences included change management, perception of hierarchy within the organization, and work ethic. These differences can create conflict when communicating, building teams, training, and engaging in career development based on how individuals work together. Proper training is needed to address the adverse impact of older workers leaving the workplace and to implement succession planning $[14,17]$.

\subsection{Generational Differences}

To understand those to whom Boomers will transfer knowledge, it was important to review other generations. These include the GI generation, Silent Generation, Generation X, and Generation Y. The following paragraphs describe these populations. The GI generation, those born before 1932, are the parents of Boomers [14]). Also known as the Veterans, this generation lived through the Great Depression of 1929 as well as World War II and experienced labor unions [16]. Their experiences influenced savings and spending patterns. The silent generation, born between 1932 and 1945 , is small in number because most men were away at war and the impact of the Great Depression resulted in fewer children. They were influenced by the Cold War and Korean War. Reared to be polite, they also stayed with one employer throughout lifetimes. This generation married early, started families, and saved money for retirement. During this time, most women did not work outside of the home [14]. Generation X, born after Boomers, between 1965 and 1976, has similarities to the Silent Generation. Born between the Boomers and Millennials, they are considered the Baby Bust generation. They watched parents work many hours for quality of life versus working hours to launch a career. Considered pragmatists, they adapt to a fast moving environment and are more ethnically diverse than their parents [4]. Generation Xers experienced single-parent homes and many were considered latchkey children. This generation is defined by the Space Shuttle Challenger explosion incident and advent of computers. Many values are shared with the Boomers such as teamwork, optimism, and personal satisfaction [16]. As conservative spenders, they save money, and have deep family roots. While self-reliant, they are also optimistic, confident, and independent. They value education and believe in parenting over work. A strong company loyalty is said to fail to exist however; there is a belief in taking skills to the best employer who fits his or her needs while seeking a work- family balance [4]. Generation Y, born between 1977 and 1994, often called the Echo Boom Generation shared similarities with the Boomer generation. Their numbers are more significant than Generation X. They have close ties with their parents. Also referred to as the boomerang kids, approximately $65 \%$ of these college graduates moved back home with parents. Diversity is taken for granted by this generation. Generation $\mathrm{Y}$ is computer literate and called true techies. This generation expects continuous feedback from friends, family, and employers because high speed and instant response is their norm [4]. Even with a short attention span, they appreciate career growth and development while focusing on working more efficiently. This group wants and needs challenging projects with deadlines that build ownership. In addition, they want flexible options that may include telecommuting or alternative solutions such as working part-time or the ability to go on leave to have children.

\subsection{Generativity}

Generativity is the "creation and maintenance of a wide range of institutional, cultural, and individual resources that are necessary to sustain the present and succeeding generations" [18]. Cox, Wilt, Olson, and McAdams [19] explained that generativity focuses on an individual's commitment and reassurance of well-being of the future generations. This concept suggested that once a human reaches the midlife period that there is a need to focus on other interests besides self and become a leader or guide to success for future generations [18]. The concept of generativity can assist organizations in preparing for the future by recognizing these differences and ensuring processes are in place to address this movement. Calo [18] suggested that organizations need to incorporate adult development programs, preretirement planning programs, and mentor roles to meet this need. Generativity is an intricate component in comprehending the midlife Boomer worker and his or her adult development. As the workforce continues to age rapidly, organizations must 
use generativity to adjust thought processes to prepare for the future. Because of the aging workforce, more attention is focused on organizational leadership and the new generational worker. Zacher, Rosing, Henning, and Frese [20] presented a concept of generativity "as leaders" behaviors and actions aimed at establishing and guiding members of the younger generation, while focusing less on their own gains, careers, and accomplishments". Senior leadership is said to demonstrate more generativity than younger leadership. Leader generativity is more significant because maintaining leadership accomplishment in mature workers was said to occur at a higher rate than in younger workers. As the workforce continues to age, it will be necessary for leaders to develop more comprehension of the function of aging workers.

\subsection{Organizational Knowledge}

Knowledge of the organization is the practical knowledge for leadership that includes services, innovation, scientific, and social knowledge. This concept forces leadership to review the ability of knowledge workers along with systems to assist the organization. Once the organization experiences the loss of knowledge, it cannot be entirely recovered. It benefits the organization to attempt to retain crucial knowledge instead of attempting to buy or recover it [21]. Organizational knowledge is separated into dynamic process or a static substance. The organizational dynamic process knowledge encompasses human actions and activities. Static substance knowledge could be articulated, exchanged, and communicated while the dynamic process knowledge worked like an operation process [22]. Calo [21] stated that the combination of explicit with tacit knowledge is one that a mature worker possesses, and that combination is one of the most strategic, significant resources of an organization. To obtain this knowledge, workers must engage in activities to understand the organization's vision and mission. Creating new knowledge, not just reviewing and reusing existing knowledge possessed by an organization is crucial. Knowledge transfer internally among the organization is a critical component for members to embrace a learning environment that creates new knowledge and learning of current knowledge. This process was explained as a unit within an organization that affects experiences of another unit. Germinal literature indicated that additional research of Baby Boomers extending their retirement may be applicable. A characteristic of Boomers is the desire to work. Some will want opportunities to continue to contribute to the organization. Organizations may want to consider recycling Boomers into the labor force on a part-time basis to assist in mentoring the new generation of workers. Creating new positions, developing career paths, and flexibility in personnel arrangements can assist in retaining knowledge. Organizations must be more proactive in establishing avenues such as adoption of job sharing, part-time work, flexible schedules, and telecommuting to adapt to the changing demographic needs of the business to encourage the stability of older workers. Along with these changes, a review of the culture is critical to enhance the method of preparing for retirement. Because of the turbulent economic states and rising health care, the aging workforce may be motivated to stay with or return to assist the organization Employee turnover will be a challenge regardless if Boomers stay or quit working. However, leadership must be able to manage the multi-generational workforce to create strategies to retain knowledgeable employees.

\subsection{Knowledge Management}

Most organizations have retirement geared toward the age of 65. Because of this notion, companies must prepare knowledge management techniques to secure their knowledge. Incorporating knowledge management into an organization's processes along with changing the culture can promote a knowledge sharing environment. While successfully assessing and obtaining knowledge may be a challenge, the changing labor demographics are forcing industries to take action. The Baby Boomers are a sizeable group in the workplace and employers are struggling to transfer their knowledge [21]. No matter how knowledge is acquired, there must be a way for it to be captured, shared, and deployed. The potential of KM can exist in capturing, retaining, and leveraging knowledge of personnel. Facilitation of knowledge transfer from older workers will enable the younger generation of workers to leverage one another's knowledge that will increase organizational efficiency and productivity.

\subsection{Human Capital}

An organization's most significant source is intellectual capital and knowledge. Intellectual capital also known as human capital is considered the value of skills, thinking, knowledge, creativity, and experiences of the workforce. As the workforce ages, workers acquire knowledge and experience customized to the operations and culture of the organization. This makes it a challenge to replace their knowledge as they exit the organization. Organizations may benefit by putting measures in place to capture and have access to human capital of the more mature workforce even if retired. Instead of concentrating on optimizing profit, the focus should be to treat information and knowledge from workers as human capital. An example is incentive pay meant to be a reward; however, it encourages the same performance but does not enhance an entrepreneurial workforce. In other words, it keeps performance at minimums and does not permit exceptional performance. The role of leadership is to be intrinsic and search for the inner motivation of employees to leverage energy and imagination. Organizations must devise strategies to assist in retaining intellectual capital of older workers. As Baby Boomers prepare for retirement, organizations need to ensure that both experience and knowledge does not retire with them. The knowledge of an organization's human capital must be captured and transferred to take advantage of the knowledge to comprehend, manipulate, and link it to an objective or purpose. The most effective way for organizations to increase competitiveness and capabilities is to retain human capital.

\subsection{Mentoring}

Mentoring can be seen as the pairing of individuals, one of whom needs to acquire the expertise or experience possessed by the other. Relationships within the organization persuade results by motivating personnel to learn from one another. Mentoring and coaching are good sources to transfer explicit and tacit knowledge because of the personal relationship and supportive culture. Most organizations take on the form of mentoring to assist in developing personnel. Mentoring can assist an organization in tapping into experience of Boomers. Senior employees may approach the mentor-mentee relationship as an opportunity to leave a legacy, or pay forward the support received from others in their own past. Organizations must recognize the important of mentors in 
transferring knowledge to the younger generation of workers as soon as possible. Establishing mentor relationships can improve communication between the generations. The relationship among the mentor and mentee creates an avenue to articulate both explicit and tacit knowledge. Additional training to promote knowledge transfer can come in the form of classroom trainer led by Boomers creating a learning environment that encourages sharing experience and leveraging various learning styles such as videos or interviewing [3]. Bozeman and Feeney [23] explained that most public sector entities promote a mentoring relationship. One of the key factors is the demographics that the public sector faces as new barriers arise as the workforce becomes older; however, there is still a need for more skills coaching and education. This demand is creating a challenge for the public sector to retain and attract workers but can be combated by successful mentoring relationships.

\subsection{Workforce Planning}

The exodus of Baby Boomers will be a challenge that the public sector is encountering and will continue to experience. Because of the high ratios of older workers, there will be a need for new knowledge workers. Those that have the necessary talent and skills may become more difficult to recruit and retain. Jacobson [24] defined workforce planning as "a process designed to ensure that an organization prepares for its present and future needs by having the right people in the right places at the right times". Workforce planning can assist the public sector with strategically preparing to face these workforce demands. This type of planning will assist organizations with their mission and values, recruiting, retention, and training. Because of demographic changes, it is essential for the government to establish a workforce planning model. The following components in the workforce planning model are: reviewing the organization's objectives, analyzing present and future workforce needs to identify necessities, developing and implementing human resources plans, and evaluating, monitoring, and adjusting the plan as necessary. Implementing and following these steps will require longterm commitment and must have the support of executive management to prepare the organization for change for decades to come [24]. Recent trends indicate that the time to plan is now. Heffes [25] explained four components contributing to the shortage in the workplace. Downsizing, aging boomers, changes in the expectations of both the employer and employee agreement, and less younger workers affected the workplace. The results of his survey indicated that $45 \%$ of organizations were not actively capturing crucial knowledge and expertise from retiring workers within the framework of any workforce planning model [25]. Organizations must recognize the issue, strategically plan, and measure progress. If organizations do not prepare a workforce plan, the organization will be impacted by a shortage of talent, skills, and human capital. Workforce planning strategies must be established to capture processes with a culture that values employees and their needs.

\subsection{Succession Planning}

To take adequate advantage of the benefits of succession planning, organizations must identify talent early to replace senior leadership positions. Shaheen [26] introduced the HIPO (highly talented individuals with promise) Paradox, a method for recognizing individuals who possess those skills, experience, and qualities needed to become a member of leadership in the organization. A method of recognizing these types of individuals was to identify key roles and identify key personnel within the organization. Greer and Virick [27] introduced several factors that should be included in an effective succession plan. Strategic integration is important within which strategies align and establish programs to identify those individuals with high potentials. Once established, these strategies must be communicated through leadership. Values must be established along with the commitment of executives to communicate those values. Accountability and authority must be established to obtain success goals. Succession planning will assist in identifying future behavioral competencies, conducting searches for talents, establishing credible mentors, and using assessments to validate objectives and learning. Competencies must be developed to ensure proper training and development to create a pool of diverse talent with use of establishing procedures and opportunities for mentor/mentee relationships. The final component is the program's management practices to monitor and identify efficient mentors to leverage skills along with incorporating performance evaluations and reward systems. Performance evaluations and reward systems could monitor success and evaluate items such as retention, development, and advancement of talent pool [27]. Succession planning is a controversial topic in both business and government leadership. Shaheen [26] argued that, "no organization has a monopoly on the best talent". Organizations spend considerable amounts on human capital to promote succession planning however; usually it is at the executive level. The success of these types of programs will depend on the leadership within the organization. Often little time is spent on creating the basics of securing the future workforce and transferring to it the knowledge of predecessors. Whereas there is succession management among the executive levels, often talent management and knowledge management are not included in the equation. Shaheen [26] emphasized that succession management should focus on implementing succession planning as well as workforce planning programs. Ndubisi [28] stated that succession planning was deemed to be very rewarding in several aspects. Benefits often incorporate personal development, increased management involvement, and compiling best practices. As Baby Boomers become retirement age, younger personnel are needed to replace vital leadership positions. Succession management was proven to be a critical component in times of retirement, resignation, or death of current leadership to assist in providing suitable leaders to ensure long business goals and survival. Shaheen [26] stated succession management can result in a competitive advantage. While the significance of succession planning is expressed, several organizations ignored the concept or did not take it seriously [28].

\section{Methodology}

The purpose of this phenomenological qualitative study was to explore knowledge transfer of 14 Baby Boomers and the methods currently used and perceived to be necessary to capture and sustain institutional knowledge in a North Texas municipality. The study addressed the emerging necessity of capturing the crucial knowledge needed to be transferred and the methods necessary to sustain institutional knowledge in a North Texas Municipality. The design of the research dictated the structure of the processes used to conduct data collection and analysis [29]. Based on the literature review, the research indicated that organizations will experience a mass exodus of Baby Boomers in the next few decades and organizations generally are ill-prepared [30]. The loss of institutional knowledge will create challenges for organizational leaders to meet work demands. This study 
included tools to explore this phenomenon in detail and results may assist organizational leaders in building leaders for the future. . A phenomenological method was used to discover data on central themes for this study. Semistructured, face-to-face interviews were used to gather data regarding the phenomena from Baby Boomer management employees. Data analysis was used to explore meanings that reveal varying perspectives of experiences and integrate those meanings into a distinctive experience. The population under investigation consisted of Baby Boomer management employees, born between 1946 and 1964 with eligibility or nearing the retirement age in a North Texas Municipality. The general population consisted of approximately 2,300 full time employees, of which nearly 800 were Baby Boomers. An estimation of 121 Baby Boomers in 14 departments of the municipality, met the criteria of being leaders born between 1946 and 1964, with the ability to retire in 10 years following the study. In this municipality, retirement was determined by age plus tenure. Typically the tenure of these individuals was greater than five years. Participants were leaders selected from a variety of work related positions in the following departments: airport, city attorney's office (CAO), community development and planning (CDP), convention center (CC) economic development (ED), financial and management resources (FMR), fire, Handitran (Transportation for seniors and the disabled), library, parks and recreation, police, public works and transportation $(\mathrm{PW})$, and water utilities. Some departments were excluded because they did not have a leader who met the participant criteria. Leaders of those individual departments were under the supervision of, answered to, and were directed by a deputy city manager, who approved the study participation of department leaders and employees. Participants provided consent to be digitally voice-recorded or were eliminated from the study.

\section{Analysis and Results}

NVivo9 ${ }^{\circledR}$ helped to conduct analyses. NVivo9 ${ }^{\circledR}$ accommodated several types of data such as audio files and text documents. This software assisted in the process of coding to discover emerging themes. For the purpose of this research study, word documents (transcripts) were imported into the system [31]. NVivo9® allowed for each interview to be created and stored for future use. Analysis of the data occurred with the use of NVivo9® qualitative software. As the study participants answered the interview questions, the results revealed eight themes which consisted of:

\subsection{Review of Themes}

\subsubsection{Theme One}

Theme one: To gather data for the perception of defining institutional knowledge, each participant was asked to define institutional knowledge. Seventy one percent of participants defined institutional knowledge as knowledge and experience whereas $29 \%$ of the participants identified institutional knowledge as history and knowledge.

\subsubsection{Theme two}

To gather data on the perception of what institutional knowledge to capture in the participant's current position, each participant commented on what institutional knowledge needs to be captured. Forty-three percent of the participants believed that institutional knowledge should be captured through planning, policies, and procedures whereas $22 \%$ believed that interpersonal experiences and relationships were relevant in capturing in his or her current position. Fourteen percent stated that it is essential to capture technical knowledge for the organization. Fourteen percent stated that experience must be captured whereas less than $7 \%$ stated "everything" is necessary to capture.

\subsubsection{Theme Three}

Knowing what knowledge to capture; Forty-three percent of the participants perceived knowledgeable about plans, agreements, and establishment of processes as essential. Twenty-two percent perceived expertise as essential to capture. Each following invariable constituent received 14\%: history not common knowledge, big picture, and purpose. Seven percent identified purpose as essential to capture.

\subsubsection{Theme Four}

Forty-six percent of the participants captured and transferred knowledge through the means of policies, procedures, and manuals. Thirty-one percent used mentoring, cross-training, training academies, shadowing, and in-house training mechanisms for capturing and transferring knowledge. Twenty-three percent used documentation and filing as methods to capture and transfer knowledge. Seven percent used business retention visits as a means to capture and transfer knowledge from the community to the organization.

\subsubsection{Theme Five}

Sixty-four percent of participants' perceived written documentation as a helpful in capturing knowledge. Twentytwo percent identified written documentation as capturing the "how" but not the "why" whereas $14 \%$ believed other methods of capturing of knowledge is necessary.

\subsubsection{Theme Six}

Twenty percent perceived lean staffing as an obstacle. Another 13\% perceived turnover and retention as obstacles whereas another $13 \%$ recognized lack of looking for knowledge and not knowing what information employees know as obstacles. The following invariable constituents were $7 \%$ for each: amount of value one has on the importance of capturing and transferring knowledge, communication, and retrieval of knowledge and system.

\subsubsection{Theme Seven}

Impact of leaving the organization; Fifty percent of the participants believed that the organization will be impacted upon his or her departure. Forty-three percent perceived there to be no impact to the organization whereas less than $7 \%$ are unsure of the impact. 


\subsubsection{Theme Eight}

Suggestions to capture and transfer knowledge; Thirty-four percent of the participants perceived mentoring, crosstraining, shadowing, and formal training as appropriate means to capture and retain knowledge. Twenty-five percent of participants believed that documentation and professional pages were essential to capture knowledge whereas $17 \%$ identified succession planning as a tool to capture and transfer knowledge. Eight percent identified the following as suggestions to capture and retain knowledge: prioritizing to determine what knowledge to capture, capturing knowledge from those who do the job and analyze the data, employee retention, and use of knowledge transfer software.

\subsubsection{Findings}

The findings from the data collection and analysis disclosed that knowledge is critical to organizational success. Results indicated that while there are some measures in place to capture knowledge such as mentoring, succession planning, and policies and procedures, as an organization there is a lack of consistency with these programs. Whereas there is awareness, more methods should be implemented to prepare for the Boomer exodus. However, the study did indicate that leaders want to share their knowledge prior to exiting the organization. Reported obstacles in transferring knowledge consisted of: (a) perception of value, communication, (b) retrieving knowledge and documents, (c) lean staffing, (d) workload/busy/distractions, (e) staff turnover/retention, (f) procedure changes, $(\mathrm{g})$ lack of looking for knowledge or knowing what employees do not know. As indicated by the literature review and participants of the study, organizations must identify key knowledge areas, create objectives for knowledge transfer, and identify those that possess crucial knowledge to transfer [32]. Organizations may suffer risks and challenges with capturing and transferring Boomer knowledge [33]. Leadership recognizes that knowledge transfer methods need to be in place. This research study suggested that leadership recognizes the possibility of the loss of Boomer knowledge and must develop knowledge transfer methods to continue organizational effectiveness $[34,35]$.

\section{Conclusion}

The workforce is more diverse and evolving. The workplace consists of four generations in the workplace together which can create challenges in any organization. To improve organizational effectiveness, generational differences must be recognized and understood by leadership. An organization's success will be determined by an ability to adopt methods that will motivate and retain personnel and attract, develop, and sustain future workers and leaders $[14,15]$. The results of this research study indicated a leadership need in establishing methods to capture, transfer, and retain institutional knowledge. The aforementioned themes can assist leadership in assessing and preparing for knowledge transfer possibilities. Leaders may gain additional insight in maintaining organizational effectiveness and operational efficiency regardless of the Boomer exodus. This study added additional research to other studies that explored experiences of Baby Boomers' perceptions of organizational readiness as they retire. Leaders are tasked with finding ways to identify, capture, transfer, and retain knowledge. Based on the results of the research study, the following suggestions will be presented to the municipality. It is suggested that the organization should establish the following for each department to capture and transfer knowledge: (a) succession planning, (b) mentoring, cross training, shadowing, formal training, (c) documentation and professional employee pages, (d) prioritizing to determine what knowledge to capture, (e) capturing knowledge from those who do the job and analyze data, (f) knowledge sharing plans and systems, and (g) employee retention plans. Each department should consult with senior staff and human resources to assess institutional knowledge and to determine the best way to capture and transfer knowledge. Devising a knowledge transfer plan will address ongoing organizational needs that will be inserted into policies and procedures. Design of the plan and system should flow around the day-to-day responsibilities to obtain work-related knowledge [32]. Kapp [32] emphasized "teachable moments" that can provide training and guidance to workers such as debriefings, hallway conversations, mentoring, and emails. When these moments occur, it is essential that they are recorded for future reference. Once a knowledge transfer plan is implemented, it is crucial to monitor the process to ensure that objectives are progressing. It is essential that organizations discover new means to capture critical information to instruct the new generational worker [32].

\section{Reference}

[1] Duncan, D. F., Nicholson, T., White, J. B., Bradley, D., \& Bonaguro, J. (2010). The baby boomer effect: Changing patterns of substance abuse among adults ages 55 and older. Journal Of Aging \& Social Policy, 22(3), 237-248. doi:10.1080/08959420.2010.485511.

[2] Magaliff, G. (2007). JVS--the economic engineer for all times. Journal of Jewish Communal Service, 82(3), 183184.

[3] Johnson, P., Indvik, J., \& Rawlins, C. (2009). Will you still love me when I'm 64 ? The boomers at work. Journal of Organizational Culture, Communications and Conflict (13), 101-107.

[4] Timmermann, S. (2007). What a difference a generation makes: How our life experiences shape our viewpoints and behaviors. Journal of Financial Service Professional, (5), 25-28.

[5] Walker-Smith, J., \& Cluman A. (2007). Generation ageless: How baby boomers are changing the way we live today... and they're just getting started. New York, NY: Harper Collins Publishers.

[6] Krepcio, K. (2007). Baby boomers in retirement. Journal of Jewish Communal Service, 82(3), 155-158.

[7] Fayol, H (1949). General and industrial management. Kingsway, London: Sir Issac Pitman \& Sons, LTD.

[8] Scott, W. R., \& Davis, G. F. (2007). Organizations and organizing: Rational, natural, and open systems. Upper Saddle River, NJ: Prentice Hall. 
[9] Drucker, P. F. (2001). The rssential Drucker. New York, NY: HarperCollins.

[10] Drucker, P. F. (1964). Managing for results. New York, NY: HarperCollins.

[11] Nishida, K. (1999). Logik des Ortes. Darmstadt, Germany: Wissenschaftliche Buchgesellschaft.

[12] Nishida, K. (1978). Intelligibility and the philosophy of nothingness. Tokyo, Japan: Maruzen.

[13] . Nonaka, I., \& Konno, N. (1998). The concept of ba: Building a foundation for knowledge Creation. California Management Review, 40(3). 40-54.

[14] Macon, M., \& Artley, J. B. (2009). Can't we all just get along? A review of the challenges and opportunities in multigenerational workforce. International Journal of Business Research, 9(6), 90-94.

[15] McNichols, D. (2008). Tacit knowledge: An examination of intergenerational knowledge transfer within an aerospace engineering community. (Doctoral dissertation). Retrieved from University of Phoenix Dissertations \& Theses Database. (AAT 3324081).

[16] Salahuddin, M. M. (2010). Generational differences impact on leadership style and organizational success. Journal of Diversity Management, 5(2), 1-6.

[17] Piansoongnern, O., \& Anurit, P. (2010). Talent management: Quantitative and qualitative studies of $\mathrm{hr}$ practitioners in Thailand. International Journal of Organizational Innovation, 3(1), 280-302

[18] Calo, T. J. (2007). Boomer generativity: An organizational resource. Public Personnel Management, $36,387-402$.

[19] Cox, K., Wilt, J., Olson, B., \& McAdams, D. (2010). Generativity, the big five, and psychosocial adaptation in midlife adults. Journal Of Personality, 78(4), 1185-1208.

[20] Zacher, H., Rosing, K., Henning, T., \& Frese, M. (2011). Establishing the next generation at work: Leader generativity as a moderator of the relationships between leader age, leader-member exchange, and leadership success. Psychology \& Aging, 26(1), 241-252.

[21] Calo, T. (2008). Talent management in the era of the aging workforce: The critical role of knowledge transfer. Public Personnel Management, 37(4), 403-416.

[22] Gao, F., Li, M., \& Clark, S. (2008). Knowledge, management, and knowledge management in business operations. Journal of Knowledge Management, 12(2), 3-17. doi:10.1108/13673270810859479.
[23] Bozeman, B., \& Feeney, M. K. (2009). Public management mentoring: What affects outcomes? Journal of Public Administration Research \& Theory, 19(2), 427-452.

[24] Jacobson, W. (2010). Preparing for tomorrow: A case study of workforce planning in North Carolina municipal governments. Public Personnel Management, 39(4), 353 377.

[25] Heffes, E. M. (2005). Dramatic workforce trends require planning. Financial Executive, 21(6), 18.

[26] Shaheen, J. (2010). Talent acquisition as a potent tool of succession management. Journal of Corporate Recruiting Leadership, 5(9), 9-12.

[27] Greer, C. R., \& Virick, M. (2008). Diverse succession planning: Lessons from the industry leaders. Human Resource Management, 47(2), 351-367.

[28] Ndubisi, N. (2010). The impact of personal culture on sophisticated succession planning by owner-managers of sme's in Malaysia. Academy of Entrepreneurship Journal, 16(2), 41-54.

[29] Leedy, P. D., \& Ormrod, J. E. (2010). Practical research: Planning and design (9th ed.). Upper Saddle River, NJ: Pearson

[30] Frey, W. (2010). Baby boomers and the new demographics of America's seniors. Generation Journal of the American Society on Aging, 34(3), 28-37.

[31] Hutchison, A., Johnston, L., \& Breckon, J. (2010). Using QSR-NVivo to facilitate the development of a grounded theory project: an account of a worked example. International Journal Of Social Research Methodology, 13(4), 283-302. doi:10.1080/13645570902996301

[32] Kapp, K. M. (2007). Tools and techniques for transferring know-how from boomers to gamers. Global Business \& Organizational Excellence, 26(5), 22-37. doi:10.1002/joe.20162

[33] Frankel, L., \& Picascia, S. (2008). Workplace legacy: Making the most of the final five. Employment Relations Today, 35(1), 1-7. doi:10.1002/ert.20182.

[34] Cappelli, P. (2008). Talent management for the twentyfirst century. Harvard Business Review, 86(3), $74-81$.

[35] Dychtwald, K., \& Baxter, D. (2007). Capitalizing on the new mature workforce. Public Personnel Management, $36,325-330$. 